\title{
Water Repellency/Proof/Vapor Permeability Characteristics of Coated and Laminated Breathable Fabrics for Outdoor Clothing
}

\author{
Hyun-Ah Kim
}

Citation: Kim, H.-A. Water Repellency/Proof/Vapor Permeability Characteristics of Coated and Laminated Breathable Fabrics for Outdoor Clothing. Coatings 2022, 12, 12. https:// doi.org/10.3390/coatings12010012

Academic Editor:

Ioannis Karapanagiotis

Received: 24 November 2021 Accepted: 15 December 2021 Published: 23 December 2021

Publisher's Note: MDPI stays neutral with regard to jurisdictional claims in published maps and institutional affiliations.

Copyright: (C) 2021 by the author. Licensee MDPI, Basel, Switzerland. This article is an open access article distributed under the terms and conditions of the Creative Commons Attribution (CC BY) license (https:// creativecommons.org/licenses/by/ $4.0 /)$
Korea Research Institute for Fashion Industry, Daegu 41028, Korea; ktufl@krifi.re.kr

\begin{abstract}
This study examined the water repellency (WR), waterproof, and water vapor permeability (WVP) characteristics of twelve types of laminated and coated woven fabrics for outdoor clothing. These characteristics were compared with the fabric structural parameters, such as cover factor, thickness, and weight, and surface modification (finishing) factors, such as coating, laminating, and Teflon treatments. In addition, an eco-friendly process for surface modification was proposed followed by a summary. Superior waterproof-breathable characteristics with $100 \%$ water-repellency were achieved in specimen 3 in group A by treatment with a hydrophilic laminated finish using nylon woven fabric with a cover factor between 0.7 and 0.9 in a 2.5-layered fabric, which was the best specimen with waterproof-breathable characteristics. A high WVP in the coated and laminated fabrics was observed in the fabrics with a low weave density coefficient (WDC) and low thickness per unit weight of the fabric, whereas superior water repellency and waterproof characteristics were observed in the high-cover-factor (WDC) fabric with appropriate fabric thickness. The determination coefficient $\left(\mathrm{R}^{2}\right)$ from regression analysis between the WVP and fabric structural parameters indicated a higher contribution of the fabric structural parameters than surface modification factors, such as coating and laminating to the WVP in the coated and laminated fabrics. Furthermore, the cover factor was the most important factor influencing the WVP of the waterproof-breathable fabrics. Of twelve coated and laminated fabrics, the laminated nylon and nylon/cotton composite fabrics showed superior WVP with high WR and waterproof characteristics. Accordingly, based on the WR, waterproof, and WVP characteristics of the coated and laminated breathable fabrics, the laminating method, as an eco-friendly process, is recommended to obtain better waterproof-breathable fabrics.
\end{abstract}

Keywords: water vapor permeability; waterproof characteristics; coated and laminated fabrics; weave density coefficient; Teflon-finished; backward regression

\section{Introduction}

Consumers who are regularly involved in outdoor activities, such as sports and leisure, or subjected to extreme conditions (snow, rain, cold, and wind) require multifunctional clothing [1], and the global market for waterproof-breathable textiles is growing annually. Such clothing should keep the wearer dry and comfortable under cold, hot, and wet conditions. To achieve this, the fabric and clothing need to be waterproof and watervapor-permeable [1]. Therefore, waterproofing and water-vapor-permeable (breathable) fabrics are used and marketed by various outdoor clothing companies with worldwide brands. The basic characteristics of water vapor permeability and waterproofing (WP), including water repellency (WR) for the famous outdoor clothing, are well known through the introduction by famous outdoor companies. Although waterproofing and breathability are commonly combined and used to imply both concepts, they are entirely different. Breathability is defined as the ability of a fabric to allow perspiration from the human body to evaporate and diffuse to the outside [2,3]. Waterproofness is an extreme case of water resistance, implying complete resistance to water [4,5]. Water repellency generally refers to the ability of a fabric to resist wetting [6]. The physical properties related to the breathable characteristics of outdoor fabrics are water repellency, hydrostatic pressure (HP) for waterproofing, and water vapor permeability (WVP), which are used in the commercial 
trade between clothing brand companies and fabric manufacturers. In addition, these experimental items are used in the protective clothing area, such as firefighter's clothing, military combat clothing, and clothing against cold and inclement weather.

Some studies [7-9] on the waterproof, water-repellent, and breathable characteristics of the coated and laminated fabrics for sports and protective clothing have been performed. The materials used in these protective clothing are called WWWW textiles because they are waterproof, water-vapor-permeable, windproof, and water-repellent. These modern materials have attempted to solve the perennial problem of keeping active humans dry while allowing perspiration vapor to escape freely [7]. WWWW materials can be classified into three main types. The first includes high-density woven fabrics called Ventile ${ }^{\circledR}$ treated with a Velan $\mathrm{PF}^{\circledR}$ finish. Modern analogs are based on tightly woven microfiber polyester fabrics treated with silicone or fluorocarbon repellent finishes [8]. The second contains microporous coatings and membranes, including Gore-Tex ${ }^{\circledR}$ based on microporous PTFE membranes with pore sizes between 0.1 and $5 \mu \mathrm{m}$, and is highly hydrophobic. Aquatex ${ }^{\circledR}$ is another microporous coating and membrane based on polyurethane chemistry [8]. The third is hydrophilic solid coatings and films, including Sympatex ${ }^{\circledR}$ based upon a modified polyester film [9]. Therefore, the fundamental physical properties of WWWW materials used in protective clothing are water-repellency, waterproofness, and water vapor permeability.

Some studies [10-13] have examined the four W characteristics of cotton, wool, PET, and nylon textile materials, and their characteristics according to the textile materials and various experimental methods for the four $\mathrm{W}$ characteristics. Of these studies, Cubric et al. [13] examined the impact of fibers, yarn, and knitted fabric structural parameters, as well as the finishing of the fabric and body activity on the water vapor resistance measured using a sweating-guarded hot plate and thermal manikin. They reported that the correlation coefficient between water vapor resistance and moisture regain was 0.7 , and the prominent structural factors of knitted fabric affecting water vapor resistance were the mass per unit area, fabric thickness, and tightness factor. Yoo and Kim [14,15] explored the effect of a layer array method in a multilayer clothing system on the vapor permeability and condensation, which was made using a simulator assessment. Gorjanc et al. [16] used thermal conductivity and water cup methods to examine the influence of elastane (Spandex) and fabric structural parameters (fabric density and weave pattern) on the thermal and water vapor resistance. They reported that elastane-incorporated cotton fabric with a twill weave has a higher thermal and water vapor resistance than conventional cotton fabric. Lee and Obendorf [17] examined the effects of the fiber materials and fabric structural parameters affecting the water vapor transport of fifteen woven fabrics using an upright cup measuring method. They reported that the fabric thickness, cover factor, void diameter, and absorption of constituent fiber were significant factors affecting the water vapor transport. Rego et al. [18] investigated the wear comfort of the elastane-incorporated cotton/polyester fabrics using a sweating-guarded hot plate method. They reported the effect of the fabric thickness and air permeability on the water vapor resistance. Many studies explored previously related to the water vapor resistance of knitted and woven fabrics have been performed using staple yarns made from cotton, polyester, and wool, as well as their blended materials.

On the other hand, Ruckmann compared the performance of different waterproofbreathable fabrics composed of nylon and PET synthetic fibers [19-21]. In addition, Ruckmann and Murray [22] examined heat loss in the external layer using zippers and openings of clothing for improved thermo-physiological comfort. In particular, Ren and Ruckman $[23,24]$ investigated the water vapor permeability and condensation in cold weather clothing. They [24] suggested a method of reducing condensation on waterproof-breathable fabric by changing its hydrophilicity. Recently, Kim [25] examined the WVP and moisture vapor resistance of 73 waterproof-breathable fabrics classified according to fiber materials (nylon and PET) and five types of surface modification methods (laminated, coated, dot laminated, hot melt laminated, and Teflon-finished). The experimental data measured using 
different measuring methods were compared in terms of the fiber materials, the fabric structural parameters, and the surface modification method. In addition, Scott [26] compared the relative performance of WWWW materials related to WVP and waterproof characteristics according to the laminating and coating methods. Several researchers [27-29] have compared the performance of WVP of different types of waterproof-breathable fabrics.

However, few studies have examined the waterproof, windproof, breathable (WWB), and four W characteristics of outdoor shell fabrics. Moreover, few studies have made an in-depth comparison between the breathable characteristics including the WR and waterproofing of laminated and coated fabrics and fabric structural parameters made of nylon and PET, including surface modification (finishing) treatment such as laminating and coating. On the other hand, the environmental impact of human beings has taken various forms, which includes pollution and energy consumption, together with global warming, rising sea levels, and the increasing frequency of adverse weather conditions [30]. Albeit a minor contributor, the textile industry is exerting some impact, and the contribution of environmental concerns in chemical processing has to be taken into account with effluents in dyehouses and the coating process. Of the surface modification methods for the waterproofbreathable fabrics, the polyurethane (PU) coating method is a kind of pollution-developing process, not an eco-friendly technology. Hence, the PU coating method is gradually being substituted with the laminating method. Many technologists in the coating and laminating manufacturers want to have information related to the differences in WR, waterproof, and WVP characteristics of different types of breathable fabrics finished with PU coating, laminating, and Teflon treatments, even though these characteristics were separately studied and published.

Therefore, the aim of this research was to examine the differences in the WR, waterproof, and WVP characteristics between coated and laminated fabrics, and an eco-friendly process for surface modification was proposed. Accordingly, in this study, twelve types of waterproof, water-repellent, and breathable fabrics were prepared, and the water-repellency (WR), hydrostatic pressure (HP), and water vapor permeability (WVP) of these fabrics were measured and compared in terms of fabric structural parameters and surface modification factors. Finally, an environmentally friendly process for surface modification was proposed to obtain better waterproof-breathable fabrics.

\section{Materials and Methods}

\subsection{Fabric Specimens}

Various types of waterproof-breathable fabric specimens, which are commercialized in the outdoor market, supplied from the coating and laminating manufacturers were used in this experiment. Twelve coated and laminated woven fabrics for outdoor clothing were prepared and classified into four groups: group A (Inno-tex, Shinpung Textiles, Daegu, Korea), nylon 6 waterproof-breathable fabrics (3 specimens), which are composed of nylon fabric materials coated with hydrophilic-type polyurethane (PU) (specimen 2), and laminated with hydrophilic-type PU (specimens 1 and 3). In particular, specimen 3 was composed of nylon fabric laminated with hydrophilic-type PU with knitted tricot at the back of the fabric (next to skin), which is called a 2.5-layered fabric; group B (Zemintex, Wonchang Materials, Daegu, Korea), PET microfiber high-density breathable fabrics (2 specimens) and PET-laminated breathable fabrics ( 2 specimens), which are composed of polyester fabrics laminated with a thin breathable film (specimens 4 and 5), and high-density PET fabrics with microfibers (specimens 6 and 7); group C (Northface, Youngone, Daegu, Korea), nylon 66 Teflon/coated breathable fabrics ( 3 specimens), which are composed of high-density nylon 66 fabric finished with Teflon (specimen 8), and nylon 66 hydrophilic and microporous PU-coated fabrics (specimens 9 and 10); group D (Monotex, Shinhung, Daegu, Korea), nylon/cotton-laminated breathable fabrics (2 specimens), which consist of nylon/cotton blend fabrics laminated with thin breathable films (specimens 11 and 12). Table 1 lists the characteristics of twelve fabric specimens. The yarn linear density and fabric density of the 
fabric specimens were measured using the experimental methods of JIS L 1096 [31]. The fabric thickness and weight were measured using JIS L 1096 [31].

Table 1. Specimens according to materials and surface modification method.

\begin{tabular}{|c|c|c|c|c|c|c|c|}
\hline \multirow{2}{*}{\multicolumn{2}{|c|}{$\begin{array}{l}\text { Specimen } \\
\text { No. }\end{array}$}} & \multicolumn{2}{|c|}{ Yarn Number (d) } & \multicolumn{2}{|c|}{ Fabric Density } & \multirow[b]{2}{*}{ Material Characteristics } & \multirow[b]{2}{*}{ Remark } \\
\hline & & Wp & Wf & $\begin{array}{c}W p \\
\text { (ends/in) }\end{array}$ & $\begin{array}{c}\text { Wf } \\
\text { (picks/in) }\end{array}$ & & \\
\hline \multirow{3}{*}{ Group A } & 1 & 80 & 83 & 232 & 120 & $\begin{array}{l}\text { Nylon hydrophilic } \\
\text { PU-laminated fabric }\end{array}$ & 2 layer \\
\hline & 2 & 56 & 71 & 170 & 93 & $\begin{array}{l}\text { Nylon hydrophilic } \\
\text { PU-coated fabric }\end{array}$ & 2 layer \\
\hline & 3 & 84 & 108 & 85 & 85 & $\begin{array}{l}\text { Nylon hydrophilic } \\
\text { PU-laminated and } \\
\text { tricot-layered fabric }\end{array}$ & 2.5 layer \\
\hline \multirow{4}{*}{ Group B } & 4 & 131 & 121 & 95 & 140 & $\begin{array}{l}\text { Polyester hydrophilic- } \\
\text { laminated fabric }\end{array}$ & 2 layer \\
\hline & 5 & 68 & 164 & 233 & 100 & Polyester-coated fabric & 2 layer \\
\hline & 6 & 56 & 65 & 212 & 130 & $\begin{array}{l}\text { Polyester microfiber } \\
\text { high-density fabric }\end{array}$ & 1 layer \\
\hline & 7 & 53 & 54 & 158 & 72 & $\begin{array}{l}\text { Polyester microfiber } \\
\text { high-density fabric }\end{array}$ & 1 layer \\
\hline \multirow{3}{*}{ Group C } & 8 & 92 & 183 & 160 & 68 & $\begin{array}{c}\text { Nylon-66 Teflon finished } \\
\text { and microfiber } \\
\text { high-density fabric }\end{array}$ & 1 layer \\
\hline & 9 & 177 & 80 & 165 & 124 & $\begin{array}{l}\text { Nylon-66 hydrophilic } \\
\text { PU-coated fabric }\end{array}$ & 2 layer \\
\hline & 10 & 89 & 178 & 152 & 70 & $\begin{array}{l}\text { Nylon- } 66 \text { microporous } \\
\text { PU-coated fabric }\end{array}$ & 2 layer \\
\hline \multirow{2}{*}{ Group D } & 11 & 41 & 272 & 118 & 83 & $\begin{array}{l}\text { Nylon/cotton- } \\
\text { laminated fabric }\end{array}$ & 2 layer \\
\hline & 12 & 64 & 67 & 120 & 108 & $\begin{array}{l}\text { Nylon/cotton- } \\
\text { laminated fabric }\end{array}$ & 2 layer \\
\hline
\end{tabular}

Note: Wp: warp, Wf: weft.

\subsection{Measurement of the Physical Properties of the Fabric Specimens}

\subsubsection{Water Repellency}

The water repellency of the fabric specimens was measured using the spray method [32]. As shown in Figure 1a, a fabric specimen of $20 \mathrm{~cm} \times 20 \mathrm{~cm}$ was laid on a $45^{\circ}$-inclined plate, and $250 \mathrm{~mL}$ of $20^{\circ} \mathrm{C}$ water in a triangle flash was sprayed on the fabric specimen for 25-30 s. The wetted fabric specimen was compared with replicas (standard samples), and the water repellency (\%) was assessed as a percentage.

\subsubsection{Waterproof by Hydrostatic Pressure Test}

The level of waterproofing by hydrostatic pressure (HP) was measured using the JIS L 1092 method [32], as shown in Figure 1b. A $15 \mathrm{~cm} \times 15 \mathrm{~cm}$ fabric specimen was prepared and clamped on the hydrostatic pressure apparatus (FX3000, Textest AG, Schwerzenbach, Switzerland). The water level ( $\mathrm{mm})$ in the manometer of a water bath was taken as the hydrostatic pressure of water leaking from the three positions on the fabric specimen clamped on the apparatus at $20^{\circ} \mathrm{C}$ in a water bath was filled at a speed of $60 \pm 3 \mathrm{~cm} / \mathrm{min}$. 


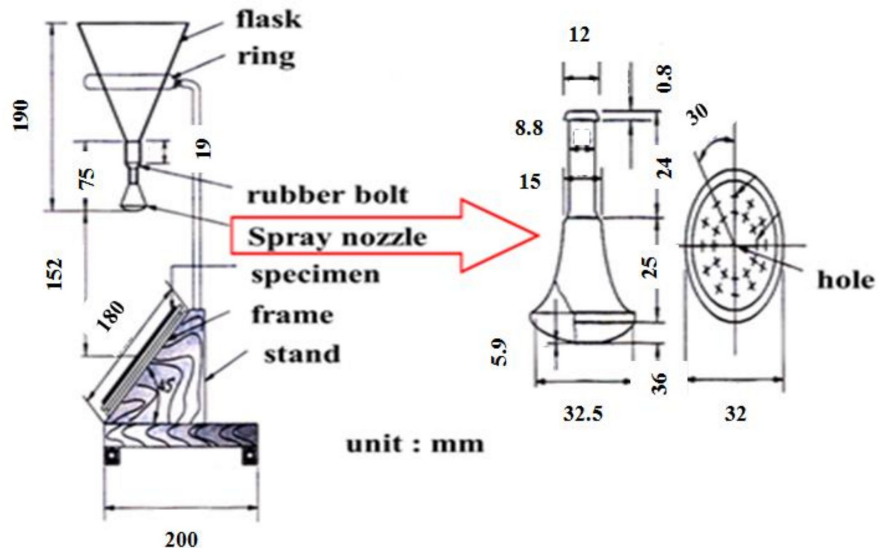

(a)

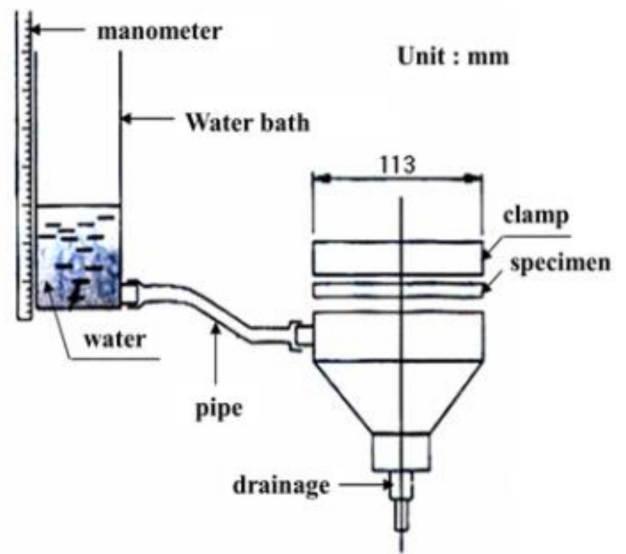

(b)

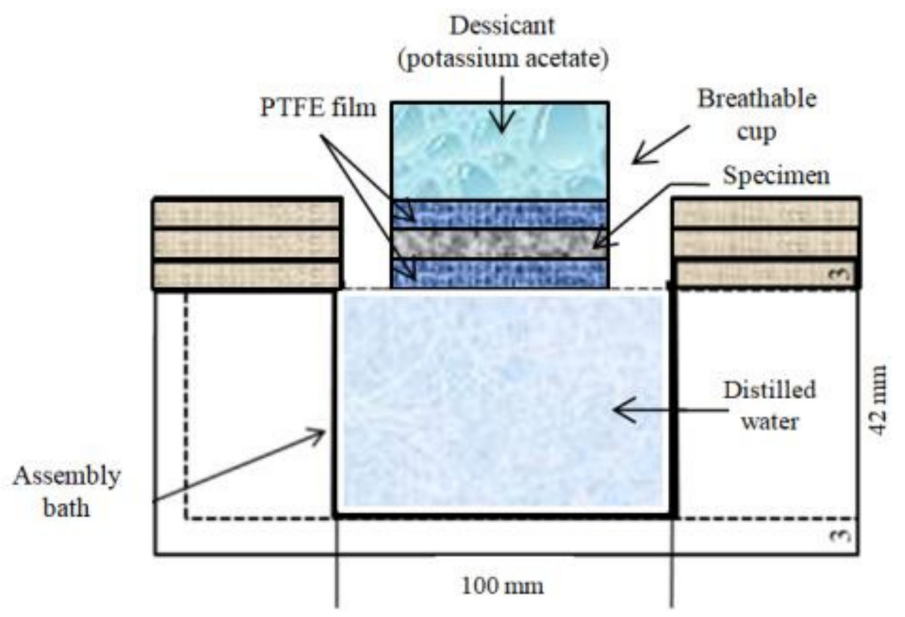

(c)

Figure 1. Schematic diagram of the water and vapor permeability measuring apparatus. (a) water repellency apparatus, Gelanots, Osaka, Japan (JIS L 1092), (b) hydrostatic apparatus, Textest AG, Schwerzenbach, Switzerland (JIS L 1092), and (c) WVP apparatus, Gelanots, Osaka, Japan (JIS L 1099).

\subsubsection{Water Vapor Permeability}

The water vapor permeability (WVP, $\mathrm{g} / \mathrm{m}^{2} \cdot 24 \mathrm{~h}$ ) of the fabric specimen was measured using the JIS L 1099 method [33]. The specimen, $8 \mathrm{~cm}$ in diameter, was prepared and conditioned at $20 \pm 1{ }^{\circ} \mathrm{C}$ and R.H of $65 \pm 5 \%$ for $24 \mathrm{~h}$. A shallow impermeable and breathable cup was prepared and filled with a desiccant agent (potassium acetate) as an absorption material. Distilled water was placed in an assembly bath with a height of $42 \mathrm{~mm}$ on which a breathable cup was laid, in which the temperature and R.H. were maintained at $40 \pm 2{ }^{\circ} \mathrm{C}$ and $50 \pm 5 \%$, respectively. The water vapor was transmitted through the fabric specimen from inside the assembly cup to the breathable cup surrounded by the desiccating agent (potassium acetate). The increase in mass of the breathable cup after a specific time has elapsed is equal to the mass of water vapor that passed through the fabric specimen. The water vapor permeability was calculated using Equation (1):

$$
\mathrm{WVP}=10 \times 24\left(\mathrm{a}_{1}-\mathrm{a}_{2}\right) / \mathrm{S}
$$

where WVP is water vapor permeability $\left(\mathrm{g} / \mathrm{m}^{2} \cdot 24 \mathrm{~h}\right) ; \mathrm{a}_{1}-\mathrm{a}_{2}$ is the mass of the breathable cup (mg) before and after the test for one hour, and $\mathrm{S}$ is the specimen area $\left(\mathrm{cm}^{2}\right)$. 


\subsection{Fabric Structural Parameter}

The weave density coefficient (WDC), as a measure of the cover factor, of the fabric specimens was calculated using the yarn linear density and fabric density shown in Table 1 , using Equations (2)-(4) [34].

$$
\begin{gathered}
\mathrm{d}=\rho_{\mathrm{f}} \times \frac{\pi \mathrm{D}^{2}}{4} \times 9 \times 10^{5} \\
\mathrm{WD} \times \mathrm{FD}=\frac{\mathrm{WDC}}{\mathrm{WF}} \times \frac{25.4^{2}}{\left(\mathrm{D}_{\mathrm{w}}+\mathrm{D}_{\mathrm{f}}\right)^{2}} \\
\mathrm{WF}=\left(\frac{\mathrm{R}+\mathrm{C}_{\mathrm{r}}}{2 \mathrm{R}}\right)^{2}
\end{gathered}
$$

where $\mathrm{d}$ is the denier; $\rho_{\mathrm{f}}$ is the fiber density; $\mathrm{D}$ is the yarn diameter $(\mathrm{mm}) ; \mathrm{D}_{\mathrm{w}}$ is the warp yarn diameter $(\mathrm{mm}) ; \mathrm{D}_{\mathrm{f}}$ is the weft yarn diameter $(\mathrm{mm})$; $\mathrm{WD} \times \mathrm{FD}$ is the warp density (ends/in) $\times$ filling density (picks/in); WDC is the weave density coefficient; WF is the weave factor; $R$ is the number of yarns in the one repeat weave; and $C_{r}$ is the number of interlacing points in the one repeat weave.

\section{Results and Discussion}

\subsection{Water Repellency of Breathable Fabric Specimens}

Some of the terms relevant to this study need to be defined. The water repellency (WR) generally refers to the ability of a fabric to resist wetting [6]. Water-repellent fabrics provide some protection against intermittent rain but are unsuitable in a downpour; water will come through under sufficient pressure. The pressure required to do so is a measure of the water-resistance [1]. Waterproofness measures the resistance of a fabric to the penetration of water under hydrostatic pressure [6], which is called a hydrostatic pressure (HP) test. Waterproofness is the extreme case of water resistance, implying complete resistance to water. Therefore, in this study, the water repellency of waterproof-breathable fabrics was measured using the spray test method, which determines the resistance to surface wetting of fabrics. On the other hand, waterproofness was measured using the HP test method as an extreme case of water resistance. Table 2 lists the physical properties of the waterproof-breathable fabric specimens. ANOVA (F-test) was carried out to verify the statistical significance of the experimental data shown in Table 2. The deviation in Table 2 stands for the difference between maximum and minimum values of five experimental data points of each specimen. ANOVA was performed between the mean value of the HP and WVP of each specimen with the $95 \%$ confidence limit ( $5 \%$ significance level). Table 3 lists the ANOVA analysis of the HP and WVP of 12 fabric specimens. As shown in Table 3, the significance test between each mean HP among 12 specimens was statistically significant, as $\mathrm{F}_{0}(\mathrm{~V} / \mathrm{Ve})>\mathrm{F}(11,48,0.95)$ and $p<0.05$. Similarly, WVP was statistically significant, as $\mathrm{F}_{0}(\mathrm{~V} / \mathrm{Ve})>\mathrm{F}(11,48,0.95)$ and $p<0.05$, as shown in Table 3.

As shown in Table 2, most specimens except for specimens 6 and 7 exhibited 100\% water repellency (WR), indicating that waterproof-breathable fabrics have water repellency, i.e., laminated and coated treatments, to obtain the breathable property accompanying water-repellent characteristics. In addition, the high-density fabric (1 layer) without laminated and coated treatments (specimens 6 and 7) exhibited 90\% water repellency. On the other hand, the high-density fabric (specimen 8) treated with a Teflon WR finish showed $100 \%$ water repellency with a low HP and WVP, which was attributed to the Teflon WR finish albeit with a one-layer fabric. According to a prior study $[1,26]$, waterproof-breathable fabrics require a water-repellent property, and the main methods for imparting water repellency to woven fabric textiles are mechanical, chemical, and coating treatments; of these methods, the water-repellent property by the mechanical method can be achieved by appropriate selection of the fabric structure and tightness, together with the appropriate fiber, yarn composition, and properties. In addition, the 90\% WR results of specimens 6 and 7 indicate a limit to the WR of high-density fabric as a mechanical method. On the 
other hand, specimen 8 treated with a Teflon finish and other coated fabrics exhibited 100\% WR values.

Table 2. Specimens according to materials and surface modification method.

\begin{tabular}{|c|c|c|c|c|c|c|c|c|c|c|c|c|}
\hline \multirow{2}{*}{$\begin{array}{c}\text { Sample } \\
\text { No. }\end{array}$} & \multirow{2}{*}{\multicolumn{2}{|c|}{ Materials }} & \multirow{2}{*}{$\begin{array}{c}\text { Surface } \\
\text { Modification } \\
\text { Method }\end{array}$} & \multirow{2}{*}{$\begin{array}{l}\text { WR } \\
(\%)\end{array}$} & \multicolumn{2}{|c|}{$\underset{\left(\mathrm{mmH}_{2} \mathrm{O}\right)}{\mathrm{HP}}$} & \multicolumn{2}{|c|}{$\begin{array}{c}\text { WVP } \\
\left(\mathrm{g} /\left(\mathrm{m}^{2} \cdot 24 \mathrm{~h}\right)\right)\end{array}$} & \multirow{2}{*}{$\begin{array}{l}\text { Structure } \\
\text { (Layers) }\end{array}$} & \multirow{2}{*}{$\begin{array}{l}\text { Cover } \\
\text { Factor } \\
\text { (WDC) }\end{array}$} & \multirow{2}{*}{$\begin{array}{l}\text { Thickness } \\
(\mathrm{mm})\end{array}$} & \multirow{2}{*}{$\begin{array}{l}\text { Weight } \\
\left(\mathrm{g} / \mathrm{cm}^{2}\right)\end{array}$} \\
\hline & & & & & Mean & Dev. & Mean & Dev. & & & & \\
\hline \multirow{3}{*}{ Group A } & 1 & Nylon & \multirow{3}{*}{$\begin{array}{c}\text { Laminated } \\
\text { Coating } \\
\text { Laminated with } \\
\text { tricot }\end{array}$} & 100 & 8720.8 & 206.1 & 8336.8 & 260.1 & 2 & 1.23 & 0.189 & 0.0110 \\
\hline & 2 & Nylon & & 100 & 5689.4 & 165.3 & 8024.2 & 276.3 & 2 & 0.96 & 0.112 & 0.0096 \\
\hline & 3 & Nylon & & 100 & $11,200.5$ & 267.2 & $12,017.2$ & 393.4 & 2.5 & 0.66 & 0.321 & 0.0137 \\
\hline \multirow{4}{*}{$\underset{B}{\text { Group }}$} & 4 & PET & Laminated & 100 & 9870.6 & 190.3 & 7542.5 & 178.1 & 2 & 1.60 & 0.256 & 0.0143 \\
\hline & 5 & PET & Coating & 100 & 5562.5 & 168.1 & 6217.8 & 179.3 & 2 & 1.09 & 0.291 & 0.0163 \\
\hline & 6 & PET & HD fabric & 90 & 762.8 & 100.3 & $11,214.2$ & 249.5 & 1 & 1.60 & 0.154 & 0.0091 \\
\hline & 7 & PET & HD fabric & 90 & 325.5 & 84.1 & $12,013.2$ & 232.4 & 1 & 1.58 & 0.117 & 0.0070 \\
\hline \multirow{3}{*}{$\underset{C}{\text { Group }}$} & 8 & Nylon & \multirow{3}{*}{$\begin{array}{l}\text { HD and } \\
\text { Teflon-finished } \\
\text { H-PU Coating } \\
\text { M-PU Coating }\end{array}$} & 100 & 821.6 & 105.3 & 2513.6 & 89.3 & 1 & 2.44 & 0.315 & 0.0110 \\
\hline & 9 & Nylon & & 100 & 2236.2 & 174.1 & 2212.5 & 80.1 & 2 & 1.33 & 0.346 & 0.0150 \\
\hline & 10 & Nylon & & 100 & 1518.8 & 126.3 & $12,112.4$ & 285.2 & 2 & 0.73 & 0.370 & 0.0150 \\
\hline \multirow{2}{*}{ Group D } & 11 & $\begin{array}{l}\text { Nylon/ } \\
\text { Cotton }\end{array}$ & Laminated & 100 & 6011.5 & 131.2 & $12,012.1$ & 378.1 & 2 & 0.81 & 0.109 & 0.0081 \\
\hline & 12 & $\begin{array}{l}\text { Nylon/ } \\
\text { Cotton }\end{array}$ & Laminated & 100 & $10,820.5$ & 379.1 & 8812.4 & 176.2 & 2 & 0.95 & 0.382 & 0.0225 \\
\hline
\end{tabular}

Note: M-PU: microporous PU. HD: high-density. H-PU: hydrophilic PU.

Table 3. ANOVA analysis of the fabric physical properties.

\begin{tabular}{cccc}
\hline Physical Properties & F-Value $\left.\mathbf{( F}_{\mathbf{0}}\right)$ & F (11, 48, 0.95) & $p$-Value \\
\hline HP & $15,617.86$ & 1.99 & $2.56 \times 10^{-81}(p<0.05)$ \\
WVP & 6410.45 & 1.99 & $4.84 \times 10^{-72}(p<0.05)$ \\
\hline
\end{tabular}

\subsection{Waterproof Characteristics of Breathable Fabric Specimens}

As mentioned previously, waterproofness is an extreme case of water resistance, and waterproofness measures the resistance of a fabric to the penetration of water under hydrostatic pressure. Accordingly, the HP test method was used to measure the waterproof characteristics of the breathable fabric specimens. Figure 2 presents HP (mean) with the deviation of twelve fabric specimens listed in Table 2. The mean value between each specimen for the HP was statistically significant, as shown in Table 3. As shown in Figure 2, hydrophilic PU-laminated nylon (specimen 1), hydrophilic PU-laminated nylon (2.5 layers) with tricot (specimen 3), laminated PET (specimens 4), and nylon/cottonlaminated (specimens 11 and 12) fabrics exhibited a higher HP than those of the PUcoated fabrics (specimens 2, 5, 9, and 10). In particular, one-layer fabrics (specimens 6, 7, and 8) showed low $\mathrm{HP}$ values below $1000 \mathrm{mmH}_{2} \mathrm{O}$, even though they are high-density fabrics, and specimen 8 treated with a Teflon finish showed 100\% WR. Specimens 9 and 10 coated with PU by hydrophilic and microporous methods showed a low HP, even though they are two-layer fabrics showing 100\% WR. However, the hydrophilic PU-coated fabric (specimen 9) showed a higher HP than the microporous PU-coated fabric (specimen 10), which is consistent with the prior finding [28]. These results suggest that the laminating method is pertinent to obtaining superior waterproof characteristics with a high HP above $6000 \mathrm{mmH}_{2} \mathrm{O}$ and superior to the coating method. This finding is in accordance with the prior study performed by Scott [26]. He reported that the waterproof property of laminated fabrics was superior to that of PU-coated fabrics, which compared the general representative groups by market leader for highest performance for WWWW materials. On the other hand, the waterproof fabrics showing an $\mathrm{HP}$ more than $6000 \mathrm{mmH}_{2} \mathrm{O}$ exhibited superior water-repellency with $100 \%$ WR. 


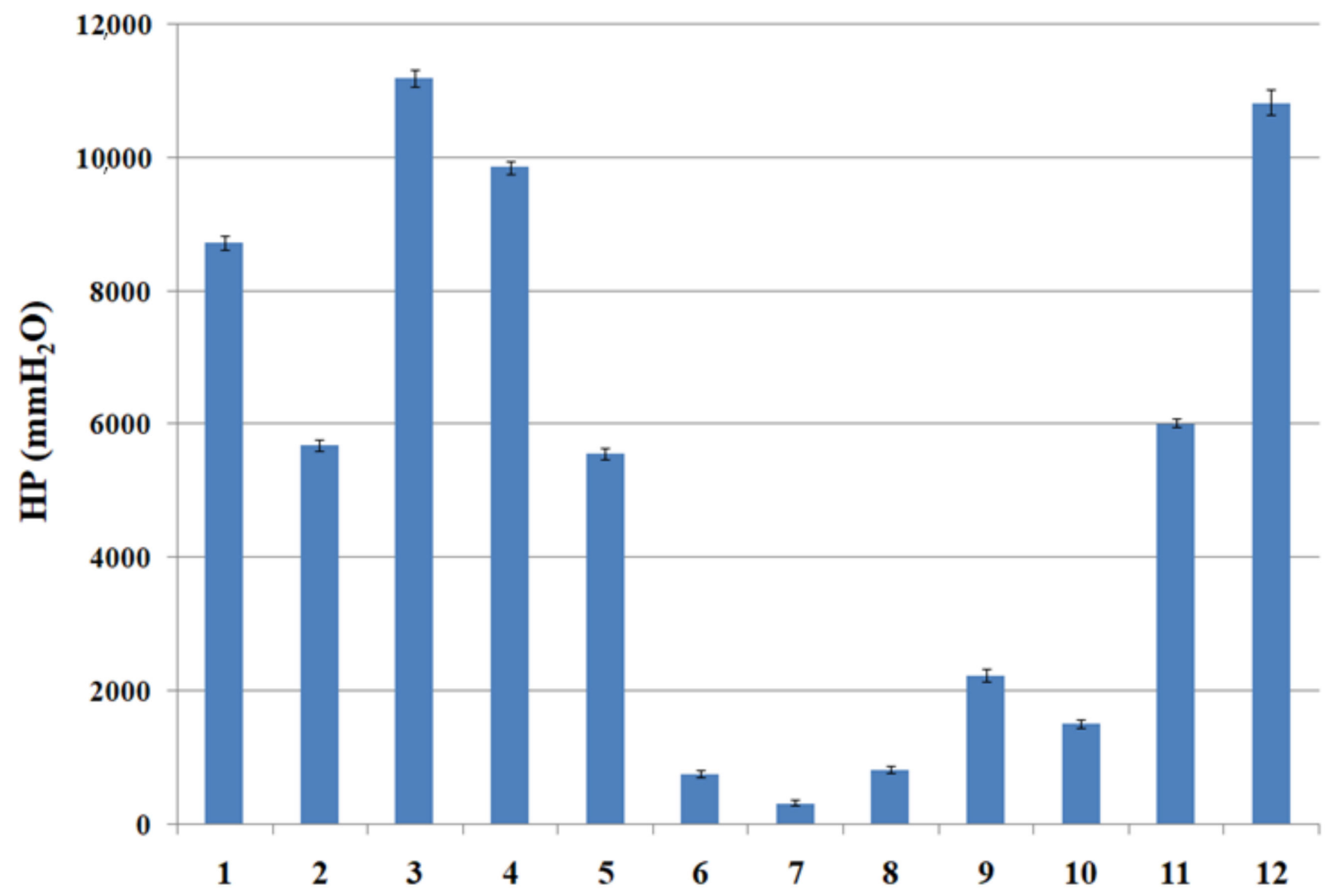

Figure 2. HP of twelve fabric specimens.

\subsection{Water-Vapor-Permeable Characteristics of Breathable Fabric Specimens}

Figure 3 presents the water vapor permeability (WVP) of the twelve fabric specimens. The mean value between each specimen for the WVP was statistically significant, as shown in Table 3. Specimens 1, 2, 3, 6, 7, 10, 11, and 12 showed a relatively high WVP above $8000 \mathrm{~g} / \mathrm{m}^{2} \cdot 24 \mathrm{~h}$. Of these, fabric specimens $3,6,7,10$, and 11 showed a superior WVP above $10,000 \mathrm{~g} / \mathrm{m}^{2} \cdot 24 \mathrm{~h}$. Specimens 6 and 7 are high-density PET fabrics with cover factors of 1.60 and 1.58, respectively. Specimens 2 and 10 are coated fabrics, and specimens 1, 11, and 12 are laminated fabrics. These results suggest that the manufacturing methods of breathable fabrics used in this study are highly dense and tightly coated and laminated fabric methods (or microporous and solid film types), which have been explained previously. Moreover, high-density PET fabrics (specimens 6 and 7) showing superior WVP exhibited a low HP and WR, which are consistent with those of a previous study [26], and the microporous PU-coated nylon fabric (specimen 10) showed a low HP with superior WVP. Except for these fabrics, the superior WVP fabrics exhibited a high HP and 100\% WR. In particular, the Teflon finish-treated and hydrophilic PU-coated fabrics (specimens 8 and 9) exhibited an inferior WVP and low HP. Hence, inferior-WVP and -WR fabrics are accompanied by a poor HP, whereas superior-WVP fabrics treated with coated and laminated finishes exhibit good waterproofing and water repellency. 


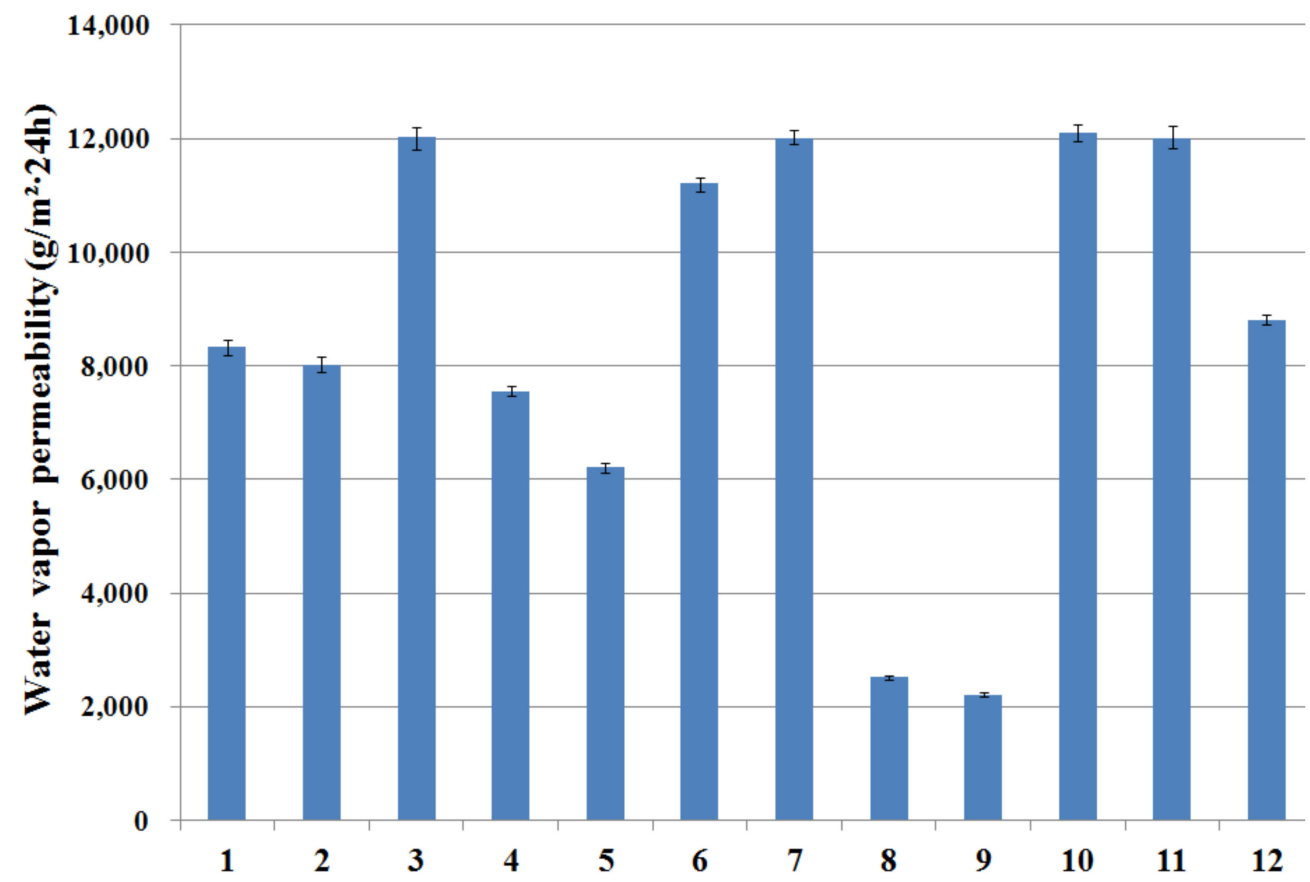

Figure 3. Water vapor permeability of 12 fabric specimens.

An examination of the WVP of four groups of specimens showed that in group A, tricot-incorporated 2.5-layer-laminated nylon fabric (specimen 3) exhibited an excellent WVP with a high HP and 100\% WR compared to the other laminated two-layer nylon fabrics (specimens 1 and 2). This highlights the importance of layers in breathable fabrics. However, even superior waterproof and breathable characteristics of 2.5-layer-laminated fabric to 2 layer ones, comfort and aesthetic qualities, such as tactile hand, drape, and visual appearance, are limited. In group B with PET breathable fabrics, the WVP of the highdensity PET fabrics (specimens 6 and 7) was much higher than that of the laminated and coated PET fabrics (specimens 4 and 5), but they exhibited a low HP and WR, which is not pertinent to waterproof-breathable fabrics, highlighting the importance of the laminated and coated finishes of the waterproof-breathable fabric. Group C was classified with three types of nylon fabrics: high-density nylon fabric with a Teflon finish (specimen 8), highdensity hydrophilic PU-coated nylon fabric (specimen 9), and low-density microporous PU-coated nylon fabric (specimen 10). The WVP of the microporous PU-coated nylon fabric (specimen 10) was much higher than those of the hydrophilic PU-coated (specimen 9) and Teflon-finished nylon (specimen 8) fabrics, but all exhibited a poor HP, demonstrating the superior breathability of the microporous PU coating compared to the hydrophilic PU one. This is in agreement with prior findings [26-28]. Scott [26] reported that the water vapor permeability of the microporous PU-coated fabrics was superior to that of the hydrophilic PU-coated fabrics. Saltz [27] also reported that the microporous PU-coated fabric exhibited a higher water vapor permeability than that of the hydrophilic PU-coated fabric. Holmes [28] also reported that the various fabrics arranged in decreasing order of WVP are PTFE laminate $>$ microporous PU coating $>$ hydrophilic coating fabrics. In group $\mathrm{D}$ with nylon/cotton-laminated breathable fabrics, the WVP of the fabric (specimen 11) with a low cover factor (WDC) was higher than that of the higher one (specimen 10). This phenomenon was found between specimens 1 and 3 in group A, between specimens 9 and 10 in group C, i.e., laminated or coated breathable fabrics with a low cover factor exhibited a high WVP. These results are consistent with the previous finding [17]. They reported that the water vapor permeability decreased with the fabric cover factor in statistical modeling analysis of water vapor transport through woven fabrics. On the other hand, the HP of the breathable fabric with a high cover factor was higher than that of the fabric with a low cover factor, which was between specimens 1 and 2, between specimens 4 and 5, between 
specimens 9 and 10, and between specimens 11 and 12, i.e., specimens 1, 4, 9, and 12 with greater cover factors showed a higher HP than did specimens 2, 5, 10, and 11 with smaller cover factors. These results suggest that a smaller cover factor indicates a better WVP but inferior waterproofing. In addition, the WR of the breathable fabric was primarily dependent on the HP of waterproof characteristics because HP (waterproof) is an extreme case of the WR, as mentioned previously. As shown in Table 2, the WR of the breathable fabrics showing an $\mathrm{HP}$ above $6000 \mathrm{mmH}_{2} \mathrm{O}$ exhibited $100 \%$ water-repellency. On the other hand, the WR of specimens 6 and 7 (1 layer) showing a low HP below $1000 \mathrm{mmH}_{2} \mathrm{O}$ exhibited a low value of $90 \%$. Specimen 8 (1 layer) treated with a Teflon finish showed a $100 \%$ WR. These results suggest that the $100 \%$ water repellency of high-density nylon fabric is due to the Teflon finish, but, even with a Teflon finish, the waterproof characteristics could not be obtained as with the high-density one-layer fabric. Hence, a coating or laminating treatment is a prerequisite to achieving a superior waterproof property above an $\mathrm{HP}$ of $6000 \mathrm{mmH}_{2} \mathrm{O}$ and $100 \%$ water repellency. In addition, superior waterproofbreathable characteristics with $100 \%$ water-repellency were achieved by treatment with a hydrophilic laminated finish using a nylon woven fabric with a cover factor between 0.7 and 0.9 , considering the water repellency, waterproofing, and breathability of a 2.5layered nylon-laminated fabric specimen (specimen 3 ), which was best specimen for the waterproof-breathable characteristics.

\subsection{Effect of Fabric Structural Parameters and Surface Modification to WVP}

The previous section showed that a water-repellent finish or coating and laminating finishes are required to achieve waterproofing or water repellency. In particular, a relevant fabric density with a multilayer is needed to achieve a breathable fabric with a high hydraulic pressure (waterproof). Therefore, the relationship between WVP and fabric structural parameters was investigated (Figure 4). Furthermore, regression analysis was carried out to determine which parameters were the most important for obtaining superior waterproof-breathable fabrics (Table 4). Figure 4 presents the WVP against the thickness/weight and cover factor of the 12 fabric specimens. As shown in Figure 4, the water vapor permeability of the breathable fabric increased with decreasing fabric cover factor and the thickness per unit weight of the fabric. In other words, a high WVP was observed in the fabrics with a low cover factor and low thickness per unit weight of fabrics in the coated and laminated breathable fabrics, which is in accordance with a previous finding [17] as mentioned previously.

Table 4. Regression analysis between the MVP and fabric structural parameters.

\begin{tabular}{|c|c|c|c|c|c|}
\hline $\begin{array}{l}\text { Water Vapor } \\
\text { Permeability } \\
\text { (WVP) }\end{array}$ & $\begin{array}{l}\text { Fabric Stuructural } \\
\quad \text { Parameter }\left(x_{i}\right)\end{array}$ & Regression Equation & $\begin{array}{l}\text { Reg. } \\
\text { Coeff. }\end{array}$ & $\mathbf{R}^{2}$ & $\begin{array}{c}p \text {-Value } \\
(\alpha=0.05)\end{array}$ \\
\hline $\begin{array}{l}\text { WVP by } \\
4 \text { vaiables }\end{array}$ & $\begin{array}{c}\mathrm{x}_{1}=\text { thickness } \\
\mathrm{x}_{2}=\text { weight } \\
\mathrm{x}_{3}=\text { thickness } / \text { weight } \\
\mathrm{x}_{4}=\text { cover factor }\end{array}$ & $\begin{array}{c}y=-312.5-81276.2 x_{1}+1127124.5 x_{2}+ \\
12016.2 x_{3}-5412.72 x_{4}\end{array}$ & 0.801 & 0.642 & 0.095 \\
\hline $\begin{array}{l}\text { WVP by } \\
5 \text { variables }\end{array}$ & $\begin{array}{c}\mathrm{x}_{1}=\text { thickness } \\
\mathrm{x}_{2}=\text { weight } \\
\mathrm{x}_{3}=\text { thickness } / \text { weight } \\
\mathrm{x}_{4}=\text { cover factor } \\
\mathrm{x}_{5}=\text { layer }\end{array}$ & $\begin{aligned} y= & 1124.2-84612.5 x_{1}+1141213.4 x_{2}+ \\
& 9376.5 x_{3}-5542.2 x_{4}-248.4 x_{5}\end{aligned}$ & 0.805 & 0.648 & 0.020 \\
\hline
\end{tabular}




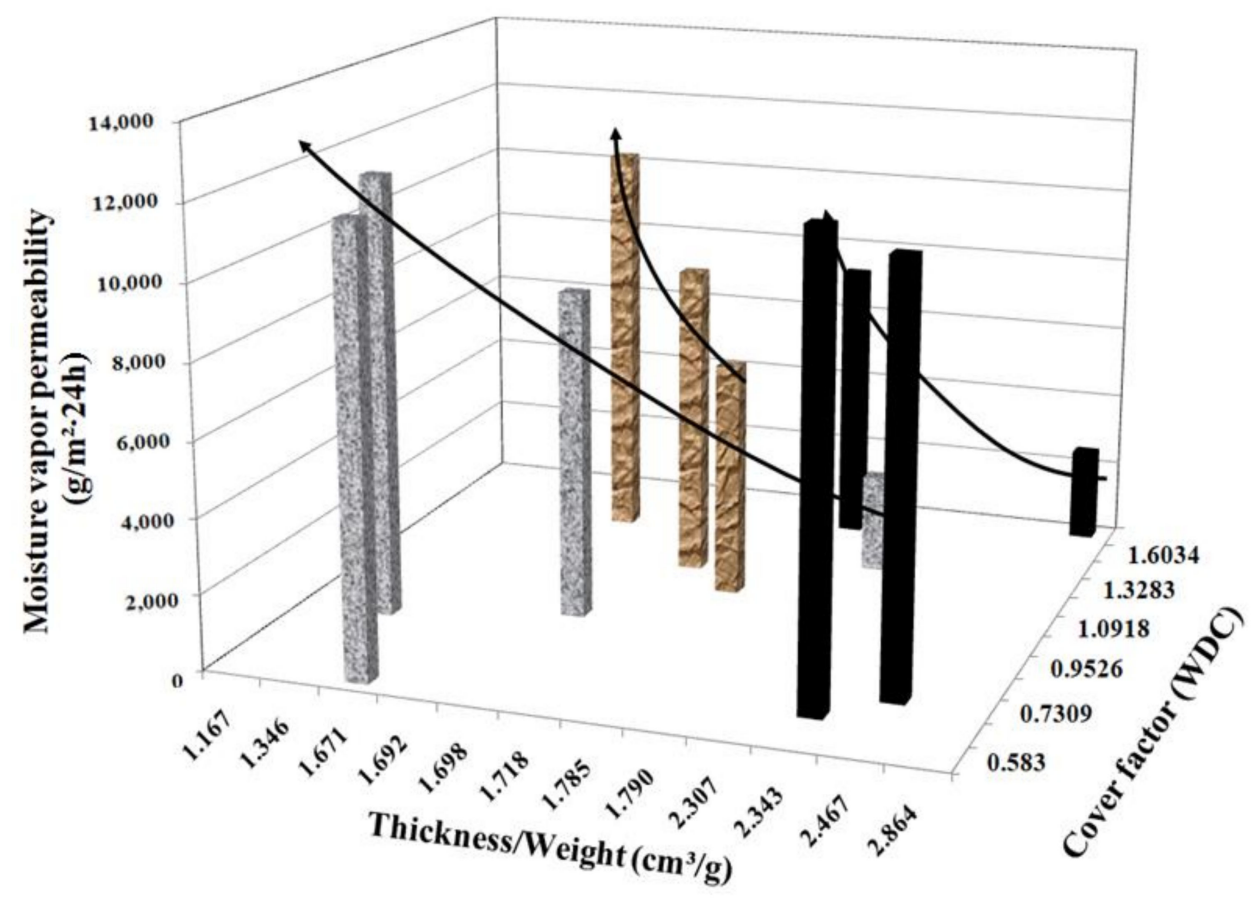

Figure 4. WVP against fabric structural parameters.

On the other hand, superior water repellency and waterproof characteristics were shown in the high-cover-factor fabric with appropriate fabric thickness, which was examined in Section 3.2. However, high-cover-factor fabrics may limit its applications for outdoor clothing because of a poor tactile hand feel due to a high cover factor. Therefore, regression analysis was performed to examine the regression coefficient and determination coefficient $\left(\mathrm{R}^{2}\right)$ of the fabric structural parameters and surface modification treatment affecting the excellent water-repellency and waterproof-breathable characteristics of breathable fabrics. Table 4 lists the regression equations, regression coefficient, and $\mathrm{R}^{2}$ between the WVP and fabric structural parameters using a backward regression. ANOVA (F-test) was carried out to verify the statistical significance of the regression result. As shown in Table 4, the WVP regression equation by four variables was statistically insignificant, as $\mathrm{F}_{0}(\mathrm{~V} / \mathrm{Ve})<\mathrm{F}(4,7,0.95)$ and $p>0.05$, but the $\mathrm{WVP}$ regression equation by five variables was statistically significant, as $\mathrm{F}_{0}(\mathrm{~V} / \mathrm{Ve})>\mathrm{F}(5,60.95)$ and $p<0.05$.

According to regression analysis, the determination coefficient $\left(\mathrm{R}^{2}\right)$ between WVP and the four types of fabric structural parameters was 0.642 with a $5 \%$ significance level, which was not significant, as $p>0.05$, but $\mathrm{R}^{2}$ between WVP and the five types of fabric structural parameters was 0.648 with a $5 \%$ significance level, which was significant as $p<0.05$ This means that the fabric structural parameters make a $64.8 \%$ contribution to the WVP, whereas the surface modification method affecting the WVP, such as coating and laminating, made a $35.2 \%$ contribution. Of fabric structural parameters, the cover factor and thickness / weight are the most important factors influencing the WVP, according to backward regression analysis, which is consistent with previous findings $[17,25]$. Lee and Obendorf [17] reported that fabric thickness, fabric cover factor, pore diameter, and moisture regain of fibers were significant parameters affecting water vapor transmission through regression analysis using fifteen woven fabrics. Kim [25] reported that the WVP of PET-breathable fabrics measured using the inverted cup method was highly dependent on the fabric density by the curvilinear regression analysis.

\section{Conclusions}

The water repellency, waterproofing, and water vapor permeability of the twelve types of waterproof-breathable fabric were examined. Their characteristics were compared and discussed in terms of surface modification, such as coating and laminating, as well as 
fabric structural parameters in terms of cover factor, thickness, and weight of fabrics. A water-repellent finish or surface modification treatment, such as coating and laminating, is a prerequisite to achieving waterproofing or water-repellency, irrespective of materials and fabric structural parameters. Of the surface modifications assessed, the laminating method is pertinent to obtaining superior waterproofing above $6000 \mathrm{mmH}_{2} \mathrm{O}$, as shown in specimens 1 and 3 in Group A, specimen 4 in Group B, and specimen 12 in Group $\mathrm{D}$ and is superior to the coating method. Superior waterproof-breathable characteristics with $100 \%$ water-repellency were achieved by treatment with a hydrophilic laminated finish using nylon woven fabric with a cover factor between 0.7 and 0.9 in a 2.5-layered fabric (specimen 3 in Group A), which was the best specimen with waterproof-breathable characteristics. A high WVP was observed in the fabrics with a low cover factor (WDC) and low thickness per unit weight of the fabric in the coated and laminated breathable fabrics, whereas superior water repellency and waterproof characteristics were observed in the high-cover-factor fabric with appropriate fabric thickness. The determination coefficient $\left(\mathrm{R}^{2}\right)$ from regression analysis between the WVP and fabric structural parameters was $64.8 \%$, with a $5 \%$ significance level. This indicates a higher contribution of the fabric structural parameters than surface modification factors, such as coating and laminating to the WVP. According to the backward regression analysis, the cover factor was the most important factor influencing the WVP of the waterproof-breathable fabrics. This regression analysis would be valid for coated and laminated breathable fabrics with specifications within the range of the specimens used in this study. While based on statistics of a specimen population, these findings are of practical use for engineering coated and laminated fabrics with high water vapor permeability. Finally, based on the WR, waterproof, and WVP characteristics of the coated and laminated breathable fabrics, the laminating method, as an eco-friendly process, is recommended for obtaining better waterproof-breathable fabrics instead of the coating method, and further studies on the effects of different types of membranes to breathability are needed in relation to the eco-friendly process for the coating and laminating treatments in the future.

Funding: This research is supported by Ministry of Culture, Sports and Tourism and Korea Creative Content Agency (Project Number: R 2019020030) and Ministry of SMEs and Startups (Project Number: S 3046102).

Institutional Review Board Statement: Not applicable.

Informed Consent Statement: Not applicable.

Data Availability Statement: Data sharing is not applicable to this article.

Conflicts of Interest: The author declares no conflict of interest.

\section{References}

1. Fan, J.; Hunter, L. Engineering Apparel Fabrics and Garments; The Textile Institute: Manchester, UK; Woodhead Publishing Ltd.: Cambridge, UK, 2009; pp. 283-308.

2. Jassal, M.; Khunger, A.; Bajaj, P.; Shnha, T.J.M. Waterproof breathable polymeric coatings based on polyurethane. J. Ind. Text. 2004, 33, 269-280. [CrossRef]

3. Tanner, J.C. Breathability, comfort and Gore-Tex Laminated. J. Coat. Fabr. 1979, 8, 312-322. [CrossRef]

4. Coffin, D.P. Stalking the perfect raincoat. Thread Mag. 1988, 19, 26.

5. Sellers, G. Breathable waterproofs under the microscope. Climb. Rambl. 1985, 24, 49.

6. Ozcan, G. Performance evaluation of water repellent finishes on woven fabric properties. Text. Res. J. 2007, 77, 265-270. [CrossRef]

7. Scott, R.A. Textiles for Protection; The Textile Institute: Manchester, UK; Woodhead Publishing Ltd.: Cambridge, UK, 2005 ; p. 601.

8. Scott, R.A. Coated and Laminated Fabrics. In Chemistry of the Textile Industry; Carr, C.M., Ed.; Blackie Academic \& Professional: London, UK, 1995; pp. 234-243.

9. Drinkmann, M. Structure \& processing of Sympatex laminates. J. Coat. Fabr. 1992, 21, 199-211. [CrossRef]

10. Huang, J.; Qian, X. Comparison of test methods for measuring water vapor permeability of fabrics. Text. Res. J. 2008, 78, 342-352. [CrossRef]

11. Gibson, P.W. Factors influencing steady-state heat and water vapor transfer measurement for clothing materials. Text. Res. J. 1993, 63, 749-764. [CrossRef] 
12. McCullough, E.A.; Kwon, M.S.; Shim, H.S. A comparison of standard methods for measuring water vapour permeability of fabrics. Meas. Sci. Technol. 2003, 14, 1402-1408. [CrossRef]

13. Cubric, I.S.; Skenderi, Z.; Havenith, G. Impact of raw material, yarn and fabric parameters and finishing on water vapor resistance. Text. Res. J. 2013, 83, 1215-1228. [CrossRef]

14. Yoo, S.J.; Kim, E.A. Effects of multilayer clothing system array on water vapor transfer and condensation in cold weather clothing ensemble. Text. Res. J. 2008, 78, 189-197. [CrossRef]

15. Yoo, S.J.; Kim, E.A. Wear trial assessment of layer structure effects on vapor permeability and condensation in a cold weather clothing ensemble. Text. Res. J. 2012, 82, 1079-1091. [CrossRef]

16. Gorjanc, D.Š.; Dimitrovski, K.; Bizjak, M. Thermal and water vapor resistance of the elastic and conventional cotton fabrics. Text. Res. J. 2012, 82, 1498-1506. [CrossRef]

17. Lee, S.S.; Obendorf, S.K. Statistical modeling of water vapor transport through woven fabrics. Text. Res. J. 2012, 82, 211-219. [CrossRef]

18. Rego, J.M.; Verdu, P.; Nieto, J.; Blanes, M. Comfort analysis of woven cotton/polyester fabrics modified with a new elastic fiber, part 2: Detailed study of mechanical, thermo-physiological and skin sensorial properties. Text. Res. J. 2010, 80, 206-215. [CrossRef]

19. Ruckmann, J.E. Water vapour transfer in waterproof breathable fabrics : I. Under steady state conditions. Int. J. Cloth. Sci. Technol. 1997, 9, 10-22. [CrossRef]

20. Ruckmann, J.E. Water vapour transfer in waterproof breathable fabrics : II. Under windy conditions. Int. J. Cloth. Sci. Technol. 1997, 9, 23-33. [CrossRef]

21. Ruckmann, J.E. Water vapour transfer in waterproof breathable fabrics : III. Under rainy and windy conditions. Int. J. Cloth. Sci. Technol. 1997, 9, 141-153. [CrossRef]

22. Ruckmann, J.E.; Murray, R. Engineering of clothing systems for improved thermophsiological comfort. Int. J. Cloth. Sci. Technol. 1999, 11, 37-52. [CrossRef]

23. Ren, Y.J.; Ruckman, J.E. Effect of condensation on water vapour transfer through waterproof breathable fabrics. J. Coat. Fabr. 1999, 29, 20-36.

24. Ren, Y.J.; Ruckman, J.E. Water vapour transfer in wet waterproof breathable fabrics. J. Coat. Fabr. 2003, 32, 165-175. [CrossRef]

25. Kim, H.A. Moisture vapor resistance of coated and laminated breathable fabrics using evaporative wet heat transfer method. Coatings 2021, 11, 1157. [CrossRef]

26. Scott, R.A. Cold weather clothing for military applications Chapter 14. In Textiles for Cold Weather Apparel; The Textile Institute: Manchester, UK; Woodhead Publishing Ltd.: Cambridge, UK, 2009; pp. 305-328.

27. Saltz, P. Testing the quality of breathable textiles. In Performance of Protective Clothing: Second Symposium; ASTM Special Technical Publication 989; American Society for Textile and Materials: Philadelphia, PA, USA, 1988; p. 295.

28. Holmes, D.A. Waterproof breathable fabrics Chapter 12. In Handbook of Technical Textiles; The Textile Institute: Manchester, UK; Woodhead Publishing Ltd.: Cambridge, UK, 2000; p. 282.

29. Holmes, D.A.; Grundy, C.; Rowe, H.D. The characteristics of waterproof breathable fabric. J. Cloth. Technol. Manag. 1995, 12, 142.

30. Kim, S.J. Moisture vapor permeability and thermal wear comfort of ecofriendly fiber-embedded woven fabrics for highperformance clothing. Materials 2021, 14, 6205. [CrossRef] [PubMed]

31. JIS L; 1096Testing Methods for Woven and Knitted Fabrics. Japanese Standards Association: Tokyo, Japan, 2015.

32. JIS L; 1092Testing Methods for Water Resistance of Textiles. Japanese Standards Association: Tokyo, Japan, 2009.

33. JIS L; 1099Test Methods for Water Vapour Permeability of Textiles. Japanese Standards Association: Tokyo, Japan, 2021.

34. Kim, S.J.; Kim, H.A. Effect of fabric structural parameters and weaving conditions to warp tension of aramid fabrics for protective garments. Text. Res. J. 2018, 88, 987-1001. [CrossRef] 